aimultaneous occurrence of these two hernix, and a critical examination of the symptoms presented may be of interest. They were: sudden and great increase in size of $\mathbf{a}$ small irreducible hernia in the left groin, followed at once by pain in the parb, vomiting, and constipation. 1. With respect to the swelling, this entirely disappeared after the reduction of the femoral epiplocele. At the time of the second operation the parts about the saphenous opening were carefully inspected, and no swelling of any kind existed at or about the situation in which an obturator hernia is known to protrude; indeed, as was afterwards shown, the knuckle of gut involved in the obturator foramen was too small to produce this sign. 2. The question as to whether the special pain existed along the course of the obturator nerve that is usually met with in these cases must remain doubtful. No inquiry was made as to such pain (the disease not being suspected), and no complaint was made of it. It is reasonable to suppose, however, that, if present, it was not severe, as she complained greably on admission of pain referred to the region of the groin and nowhere else, and the morning after the first operation expressed herself as being free from pain. 3. With regard to the vomiting, no accurate information could be obtained about this symptom prior to admission beyond the fact that it had occurred, and the patient was not sick in the interval which elapsed between her admission into the hospital and the time of the first operation. It should also be noted that the vomiting which occurred twice after this operation, and which I attributed to the effects of the anæsthetic, was absolutely non-feculent in character, consisting simply of the contents of the stomach, feculent vomiting appearing suddenly on the second day after operation. 4. The constipation, it will be remembered, was not absolute. Although there had not been any movement of the bowels for forty-eight hours previous to admission, yet she had during that time passed flatus, and continued to do so on the day after operabion. At this time her bowels were well moved after an enema, and there was another slight motion on the following day. All these anomalous symptoms, which made me doubt at the time that there was anything more than the severely constricted epiplocele to account for them, were probably caused by the fact that a portion of the calibre of the intestine had escaped strangulation and had allowed flatus and some liquid fæces to pass. Daath resulted in this case from the inability of an aged and feeble person to bear the shock of the second operation; excepting for this, no reason was disclosed at the post-mortem examination why she should not have recovered. The fact that obturator hernire usually occur in elderly persons, especially females, together with the difficulties in diagnosis, even when the case is not complicated, and the frequent delay in operating that consequently ensues, no doubt accounts for the very high mortality that has bitherto prevailed in such cases.

Nottingham.

\section{Clinital athotes:}

\section{MEDICAL, SURGICAL, OBSTETRICAL, AND THERAPEUTICAL.}

\section{CHOREA FOLLOWING INFLUENZA IN A WOMAN AGED SIXTY-FIVE}

BY P. A. McCaRTHy, M.D., M.CH., M.A.O. (R.U.I.), \&c.

ON Jan. 26th I was called in to see Mrs. A. C-, aged sixty-five. She had been feeling unwell for some time previously, but had taken to bed only the day before. The usual symptoms of influenza were present, together with a slight cough. Temperature $101^{\circ} \mathrm{F}$. In a few days the cough had gone and the temperature fallen to normal, but the prospration was very great and anorexia almost complete. It was with difficulty she could be persuaded to take nourishment of any kind; she "felt that she did not want it," and "everything had the same salty taste." She complained also of nausea and a burning pain in the pit of the stomacb, and suffered a good deal from flatulence. To relieve these symptoms pepsine was given, effervescing draughts, ice, and mixtures containing soda, bismuth, hydrocyanic acid, \&c., followed by quinine, strychnine, bark, dialysed iron, brandy, and champagne, but with very little benefit. For two weeks she continned in much the same condition, now showing slight improvement, again relapsing, but making no decided progress towards recovery. On Feb. 23rd choreic movements began in the fingers of the right hand, and three days later all the muscles of the arm and face had become involved.' The arm was jerked about so violently that it was found necessary to secure it, the skin being broken in places. Her speech was much im. paired, and she had to be fed from a feeding cup. Liquor arsenicalis was given, and she was put on milk, liquor carnis, peptonoids, peptonised cocoa and milk, brandy, and port wine. On the morning of March 6th the movements had enolrely ceased, leaving the patient in a very exhausted condition, from which she never rallied; she grew gradually weaker, and died on March 11 th. In her youth she had an attack of diphtheria, followed by paralysis of the right arm, lasting some months. Kempsey, Worcester.

\section{PHLEGMASIA DOLENS FOLLOWING INFLUENZA.}

\section{By C. Alex. Ducket, M.R.C.S.}

Although phlegmasia dolens is a disease which occurs chiefly in the puerperal state, I have seen it lately in three cases of influenza, all of which bore striking resemblance to each other. Instead of the temperature going down, as is usual in an uncomplicated case, it kept up. There was great pain in the groin and upper part of the thigh, quickly followed by swelling, which extended over the whole limb. This rapidly increased, so that in two days the limb was twice as large as the non-affected one. The swelling was of a very solid nature, and did not pit upon pressure. There was not the least alteration by raising the leg. This state of things lasted for ten days, under the usual treatment, when the pain grew less, the limb softer, and the temperature fell to $99 \cdot 8^{\circ}$. All three patients were affected in the left lower extremity, and were very restless. The obstructed vessels could be easily felt as hard cords. I may mention that the above pabients were not subject to varicose veins, and, although married women with families, were never before troubled with their legs. The frequency of phlegmasia dolens in the lying-in period is attribuced to the combination of slowness of the circulation with a varicose condition of the veins plus an extra amount of fibrin in the blood. May we not have exactly such a state of things during influenza? Lavenham, Suffolk.

\section{SOME CASES OF ABNORMAL SWEATING.}

\section{By L. Frazer-Nasi, L.R. C.P. \& S. Ed.}

CASE 1.-Amongst the patients who were attending the Hyderabad Dispensary in 1888 was a Hindu boy, upon whose skin was a crystalline deposit, more or less generally distributed, which suggested the idea that the boy had bathed in a saturated solution of some salt that had been allowed to dry on him. The crystals were glistening and amorphous to the naked eye, and required some friction to be removed dry. The family history was unimportant. The boy, who was ten years old, had suffered more or less since babyhood from malaria, and for four or five years his mother had noticed these white sweats, which, she said, occurred while he slept. I never found his skin other than dry, although he attended the dispensary for debility during some of the hottest months. The efflorescence was most marked on the legs, and notably over the shins; the crystals were also largely deposited on the back. About the head the crystals were coarser than elsewhere. The boy was thin, with flabby muscles, and his back was covered with rather long downy hair. The heart and lungs were apparently healthy. The urine, which I examined on one occasion only when the efflorescence was fully marked, was acid, sp. or. 1008; no change on boiling. The microscope showed the usual phosphates. I tried to examine the skin deposit under the microscope, but failed to get more than epithelial scales and amorphous crystals. I regret to say I did not test the latter chemically, and, owing to press of work, was not able to take notes as fully as I could have wished. After a 